\title{
A Key Power Trade-off in Wireless EEG Headset Design
}

\author{
David C. Yates and Esther Rodriguez-Villegas
}

\begin{abstract}
The development of wireless ambulatory EEG is crucial in enabling the longer term monitoring of a patient in their everyday environment. The analysis presented here will aid the designer of a wireless EEG headset in improving the ratio of battery lifetime to battery size, with the aim of minimising the size and weight of the device. Data compression is proposed as a method to reduce the power used by the wireless transceiver, shown to dominate the system power budget. Graphs are presented which show the power available to perform varying degrees of compression in order to achieve the required lifetime or battery volume.
\end{abstract}

\section{INTRODUCTION}

Electroencephalography (EEG) is an important tool in the diagnosis and treatment of neurological diseases such as epilepsy [1]. A routine EEG normally consists of a 20 minute sampling of the patient's brain waves, which is usually too brief to capture any actual events [2]. Where diagnosis is uncertain longer term EEG monitoring is necessary, which often has to be done through inpatient admission. This is costly, not universally available and removes the patient from their everyday environment, which may well contain the triggers for the abnormal events [2].

Ambulatory EEG (AEEG) provides an opportunity for the patient to be monitored at home. In such a system the electrodes are connected to a portable recording unit, which is worn on the belt or an over-the-shoulder pouch [2]. Despite recent advances in AEEG, current models are still unsuited to monitoring for much longer than $24 \mathrm{hrs}$ due to limited battery lifetime and data storage capability, the difficulty of the patient removing and replacing electrodes, the cosmetically uninspiring look of the system and the restrictive nature of a wired headset [2], [3]. There exist cases when it would be extremely beneficial to perform longer term monitoring over a period of weeks or even months [3].

The development of a wireless AEEG headset is key to achieving longer term monitoring, by improving the usability, comfort and look of the system. This will increase the number of settings in which the patient will be willing or able to use the headset. Particularly important for longer term monitoring is that the patient continues going to work whilst using the AEEG system.

Minimising the size and weight of the wireless AEEG headset is key to its success. This places stringent limits on the battery size and hence the power consumption. This paper identifies and analyses a key trade-off in order to increase the lifetime to battery size ratio.

The authors are with the Department of Electrical and Electronic Engineering, Imperial College London, London SW7 2AZ.

\{david.yates, e.rodriguez\}@imperial.ac.uk

\section{SYSTEM POWER CONSUMPTION}

Figure 1 shows how the battery lifetime depends on power consumption for three groups of off-the-shelf batteries, which have been classified based on the total energy available. Table I details the three groups, which have been named AA, the large coin cell (LCC) and the small coin cell (SCC), and provides examples of each. Included in the examples are both primary and secondary cells denoted in the table by $(\mathrm{P})$ and (S) respectively.

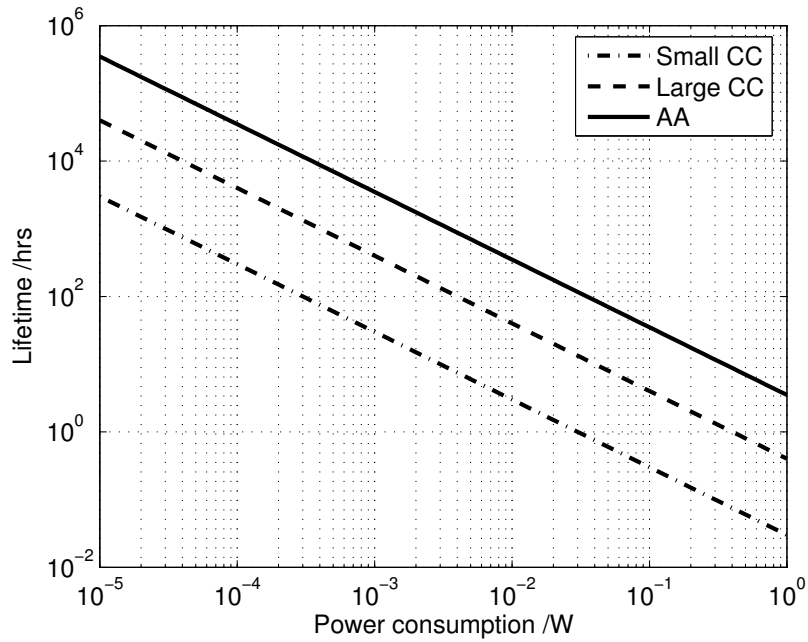

Fig. 1. Lifetime versus power consumption.

A number of groups have designed wireless headsets based on off-the-shelf components. One representative prototype, developed by IMEC [4] consumes $145 \mathrm{~mW}$, which would require an AA battery to achieve a lifetime of a few days (see figure 1). It is likely that successful AEEG wireless headsets would have to operate off a much smaller battery, in which case the power consumption must be significantly reduced.

The electronics in a wireless AEEG headset consists of at least an amplifier, an ADC and a radio transmitter. Recently ultra low power amplifiers for EEG systems have been reported which achieve the required performance whilst dissipating only around $1 \mu \mathrm{W}$ [5], [6]. A sub-microwatt ADC suitable for the application is presented in [7]. Assuming that there are between 24 and 32 channels, which is standard for current AEEG systems [2] and each channel requires one amplifier and one ADC, the total power consumed by these two circuit blocks will be no more than about $60 \mu \mathrm{W}$.

Table II shows the power consumption and data rates of various 'state-of-the-art' low power transceivers. Where the 


\begin{tabular}{|c|c|c|c|c|c|c|}
\hline Group & Energy & \multicolumn{5}{|c|}{ Examples } \\
\hline & & Make & Type & Voltage & Capacity & Size $($ diam. $\times$ height $)$ \\
\hline AA & $3500 \mathrm{mWh}$ & Sanyo HR-3U-4BP & NiMH $(\mathrm{S})$ & $1.2 \mathrm{~V}$ & $2500 \mathrm{mAh}$ & $15 \mathrm{~mm} \times 51 \mathrm{~mm}$ \\
\hline AA & $3500 \mathrm{mWh}$ & Duracell Ultra MX1500 & Alkaline $\mathrm{MnO}_{2}(\mathrm{P})$ & $1.5 \mathrm{~V}$ & $2500 \mathrm{mAh}$ & $15 \mathrm{~mm} \times 51 \mathrm{~mm}$ \\
\hline LCC & $400 \mathrm{mWh}$ & VARTA & NiMH $(\mathrm{S})$ & $1.2 \mathrm{~V}$ & $250 \mathrm{mAh}$ & $25.1 \mathrm{~mm} \times 6.7 \mathrm{~mm}$ \\
\hline LCC & $400 \mathrm{mWh}$ & Panasonic & LiMnO $_{2}(\mathrm{P})$ & $3 \mathrm{~V}$ & $165 \mathrm{mAh}$ & $20 \mathrm{~mm} \times 2.5 \mathrm{~mm}$ \\
\hline SCC & $30 \mathrm{mWh}$ & RS RX364-2C5 & $\mathrm{AgO}_{2}(\mathrm{P})$ & $1.5 \mathrm{~V}$ & $23 \mathrm{mAh}$ & $6.8 \mathrm{~mm} \times 2.15 \mathrm{~mm}$ \\
\hline SCC & $30 \mathrm{mWh}$ & Power Paper STD-1 & $\mathrm{ZnMnO}_{2}(\mathrm{P})$ & $1.5 \mathrm{~V}$ & $15 \mathrm{mAh}$ & $39 \mathrm{~mm} \times 0.6 \mathrm{~mm}$ \\
\hline
\end{tabular}

TABLE I

SPECIFICATIONS FOR BATTERIES OF DIFFERENT SIZES.

required data rate is significantly less than the achievable data rate the transmitter can be operated at a low duty cycle, considerably reducing the average power dissipation. The energy used per bit transmitted, also given in table II, is therefore a useful metric. Two energy per bit values are used in the remainder of this paper. Based on the performance of the nRF2401 [8] and the BRF6150 [9], 50 $\mathrm{nJ} / \mathrm{b}$ is taken as a conservative value, definitely achievable in most environments for short range communications, whereas $5 \mathrm{~nJ} / \mathrm{b}$ is taken as a more speculative but still realistic figure, based on the reported performance of UWB devices such as the XS110 [10] or on cutting edge narrowband device such as Zarlink's ZL70100 [11].

\begin{tabular}{|c|c|c|c|c|}
\hline & $\begin{array}{c}\text { nRF2401 } \\
{[8]}\end{array}$ & $\begin{array}{c}\text { BRF6150 } \\
{[9]}\end{array}$ & $\begin{array}{c}\text { XS110 } \\
{[10]}\end{array}$ & $\begin{array}{c}\text { ZL70100 } \\
{[11]}\end{array}$ \\
\hline Type & GFSK & Bluetooth & UWB & MICS \\
\hline Data rate (b/s) & $1 \mathrm{M}$ & $1 \mathrm{M}$ & $110 \mathrm{M}$ & $800 \mathrm{k}$ \\
\hline TX power $(\mathrm{mW})$ & 21 & 75 & 750 & 5 \\
\hline Energy/bit $(\mathrm{nJ} / \mathrm{b})$ & 21 & 75 & 6.8 & 6.25 \\
\hline
\end{tabular}

TABLE II

LOW POWER OFF-THE-SHELF TRANSCEIVERS

Based on 32 channels, a sampling rate of $200 \mathrm{~Hz}$ and a resolution of 16 bits [2], the required data rate of current AEEG systems is approximately $100 \mathrm{~kb} / \mathrm{s}$. This can be reduced to only $64 \mathrm{~kb} / \mathrm{s}$ by removing the large DC offset at the scalpelectrode interface, which is almost 1000 times the signal amplitude [12]. This corresponds to a transmitter power consumption of $3.2 \mathrm{~mW}$ in the conservative case and 320 $\mu \mathrm{W}$ in the speculative case. It can thus be clearly seen that the transmitter will dominate the system power consumption in both cases, and this is neglecting the power needed to control the transmitter or store the data to be transmitted.

\section{DATA COMPRESSION}

In order to reduce the power consumption of the system it is necessary to dissipate less power in the transceiver. One way to achieve this is to reduce the amount of data to be transmitted. Duty-cycling the transmitter according to the ratio of the required data rate to the maximum data rate results in the following average transmitter power consumption, $P_{T X, u}$ :

$$
P_{T X, u}=\frac{b_{r, u}}{b_{r, \max }} \cdot P_{T X, \max }
$$

where $b_{r}, u$ is the required data rate before compression, $b_{r, \max }$ is the maximum possible data rate and $P_{T X, \max }$ is the transmitter power consumption at that maximum data rate. Using the same argument, compressing the data will result in an average transmitter power dissipation, $P_{T X, c}$, which is given by:

$$
P_{T X, c}=\frac{b_{r, c}}{b_{r, u}} \cdot P_{T X, u}
$$

where $b_{r, c}$ is the required data rate after compression.

The compression technique will consume a certain amount of power, $P_{\text {comp }}$, which includes any extra short term data storage and duty cycle control of the transceiver. The total system power consumption, $P_{s y s}$ is thus given by:

$$
P_{s y s}=P_{a m p}+P_{A D C}+P_{c o m p}+C \cdot P_{T X, u}
$$

where $P_{a m p}$ are $P_{A D C}$ are the power consumption of the amplifiers and $\mathrm{ADC}(\mathrm{s})$ respectively; $C$ is the compression ratio, which is equal to $b_{r, c} / b_{r, u}$. If $P_{c o m p}+C \cdot P_{T X, u}<P_{T X, u}$ then the total system power is reduced. Reducing $C$ will generally require an increase in $P_{\text {comp }}$. The remainder of this paper analyses this key design trade-off by detailing the combinations of $C$ and $P_{\text {comp }}$, which will improve the lifetime to battery size ratio.

Figure 2 shows the proposed architecture of the AEEG system for 2 channels. E1 and E2 are the channel electrodes and REF is the reference electrode. Comp is the compression block and TX represents the wireless transmitter.

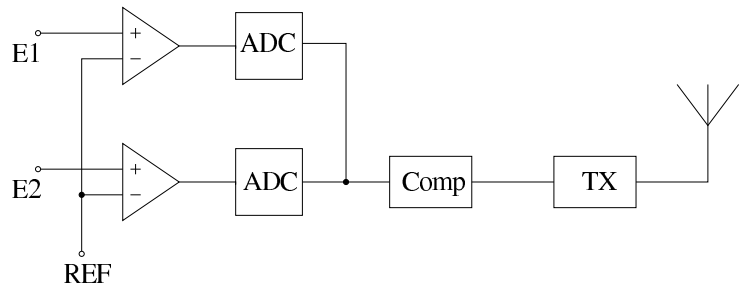

Fig. 2. Proposed wireless AEEG architecture shown for 2 channels.

\section{IMPROVING BATTERY LIFETIME}

For a battery powered system, designed to operate for a lifetime, $t_{l}$ the total system power is given by:

$$
P_{\text {sys }}=\frac{C_{\text {cell }} \cdot V_{\text {cell }}}{t_{l}}
$$

where $C_{\text {cell }}$ is the battery capacity and $V_{\text {cell }}$ is the battery voltage. Figures 3 and 4 show the system designer which 
combinations of $P_{\text {comp }}$ and $\mathrm{C}$ will be required to achieve a certain lifetime for a given amount of available energy. Both graphs assume a total amplifier and ADC power consumption of $60 \mu \mathrm{W}$ and that the uncompressed data rate is $64 \mathrm{~kb} / \mathrm{s}$. The lifetime is normalised with respect to the available energy of the battery given by $C_{\text {cell }} \cdot V_{\text {cell }}$. Table III shows the lifetime for the different battery groups of table I with and without compression. The table gives specific values of a realistic compression ratio and $P_{\text {comp }}$ combination which would result in a useful but reasonable increase in lifetime. $t_{l, c}$ and $t_{l, u}$ represent the battery lifetime with and without compression respectively.

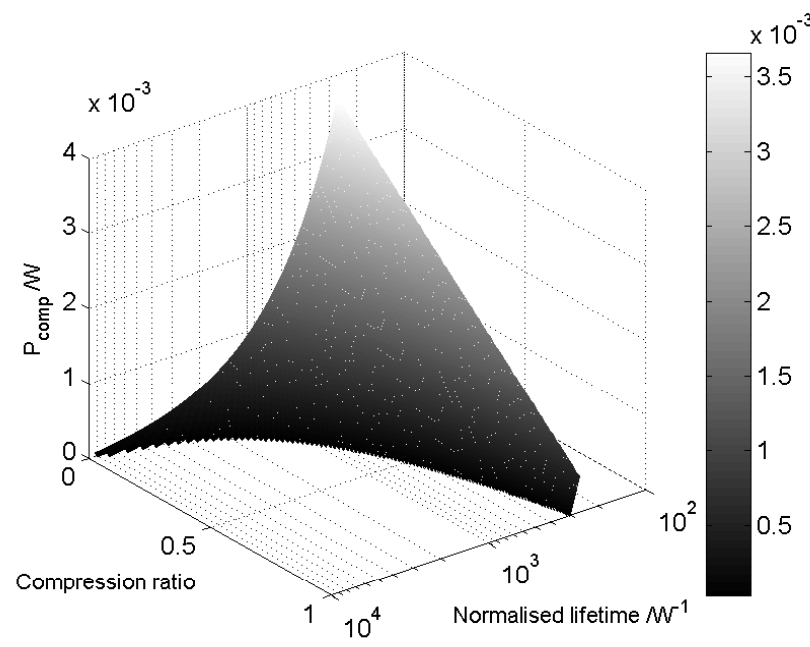

Fig. 3. Maximum power for compression against compression ratio and normalised lifetime for a transmitter which consumes $50 \mathrm{~nJ} / \mathrm{b}$.

The figures of table III are promising in that even for the conservative estimate of transmitter power, if compression ratios of around 0.25 can be achieved for no more than 200 $\mu \mathrm{W}$ then the SCC battery class could operate for $24 \mathrm{hrs}$, which would be the same as many current AEEG systems, and the LCC battery class could operate for 2 weeks, which is much longer than current AEEG devices.

\section{Reducing BAtTery Volume}

The advantages of data compression can also be quantified in terms of the reduction in battery volume for a given lifetime. Figures 5 and 6 show the combinations of $P_{\text {comp }}$ and $\mathrm{C}$ required for a particular battery volume based on the energy density of a lithium secondary cell, which is 1100 $\mathrm{J} / \mathrm{cc}$ [13]. Battery volume has been normalised to lifetime measured in hours. It can be seen from figure 5 that to achieve a volume to lifetime ratio of less than $0.01 \mathrm{~cm}^{3} / \mathrm{h}$, data compression is needed for a transmitter which consumes $50 \mathrm{~nJ} / \mathrm{b}$. Figure 6 shows that for the $5 \mathrm{~nJ} / \mathrm{b}$ transmitter no compression is needed until the desired volume to lifetime ratio drops below about $0.0012 \mathrm{~cm}^{3} / \mathrm{h}$. Figure 7 shows that for a data compression of 0.4 at a power of $0.5 \mathrm{~mW}$, the battery size could be almost halved.

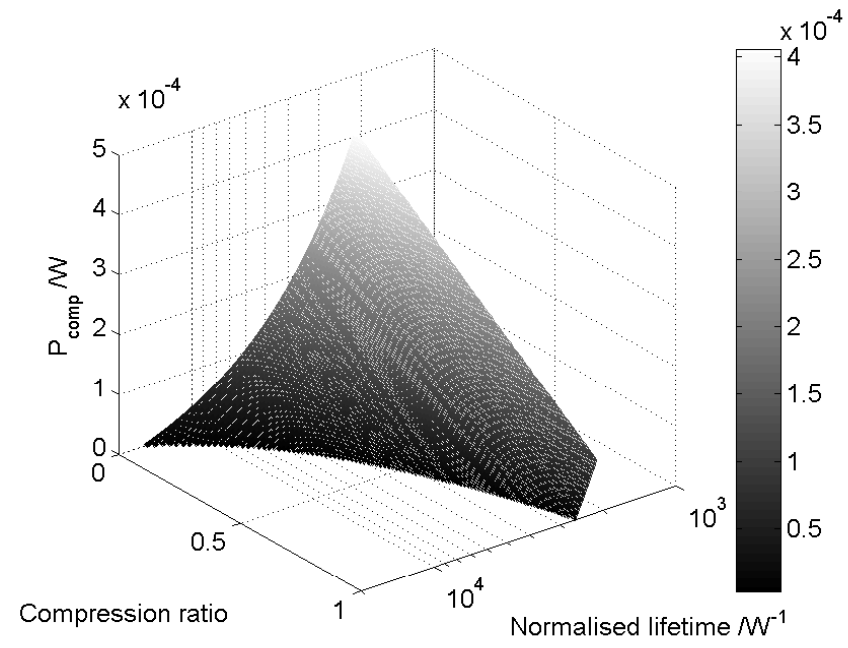

Fig. 4. Maximum power for compression against compression ratio and normalised lifetime for a transmitter which consumes $5 \mathrm{~nJ} / \mathrm{b}$.

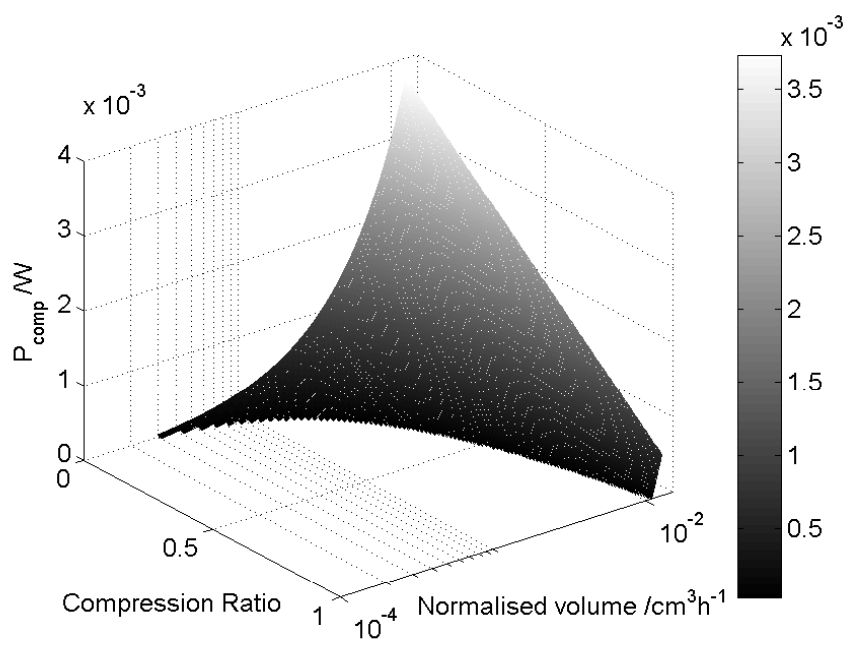

Fig. 5. Maximum power for compression against compression ratio and battery volume normalised to lifetime for a battery with energy density equal to $1100 \mathrm{~J} / \mathrm{cc}$, and a transmitter which consumes $50 \mathrm{~nJ} / \mathrm{b}$.

\section{Possible Methods of Data Compression}

Various data compression techniques for EEG signals are presented and compared in [14]. As an example, Huffman coding combined with derivative computation is shown to achieve a compression ratio of 0.4 for low computational complexity [14]. A lossy compression technique presented in [15] achieves compression ratios of 0.1 to 0.2. Another promising method is to utilise the mutual information that exists between channels [16]. Figures 3, 4, 5 and 6 demonstrate that the challenge for the designer is to implement such algorithms at sub-milliwatt power levels.

\section{CONCLUSION}

Graphs have been presented which aid the designer in determining when it is advantageous to employ data compression. These graphs show the improvement in lifetime 


\begin{tabular}{|c|c|c|c|c|c|}
\hline TX Energy/bit & Group & $t_{l, u}$ & $t_{l, c}$ & $\mathrm{C}$ & $P_{c o m p} / \mathrm{mW}$ \\
\hline $50 \mathrm{~nJ} / \mathrm{b}$ & SCC & 9 hrs & 24 hrs & 0.3 & 0.23 \\
\hline $50 \mathrm{~nJ} / \mathrm{b}$ & LCC & 5 days & 2 weeks & 0.2 & 0.17 \\
\hline $50 \mathrm{~nJ} / \mathrm{b}$ & AA & 6 weeks & 12 weeks & 0.4 & 0.4 \\
\hline $5 \mathrm{~nJ} / \mathrm{b}$ & SCC & 3 days & 1 week & 0.2 & 0.05 \\
\hline $5 \mathrm{~nJ} / \mathrm{b}$ & LCC & 6 weeks & 12 weeks & 0.3 & 0.04 \\
\hline $5 \mathrm{~nJ} / \mathrm{b}$ & AA & 1 year & 3 years & 0.2 & 0.009 \\
\hline
\end{tabular}

TABLE III

COMPARISON OF BATTERY LIFETIME WITH AND WITHOUT DATA COMPRESSION

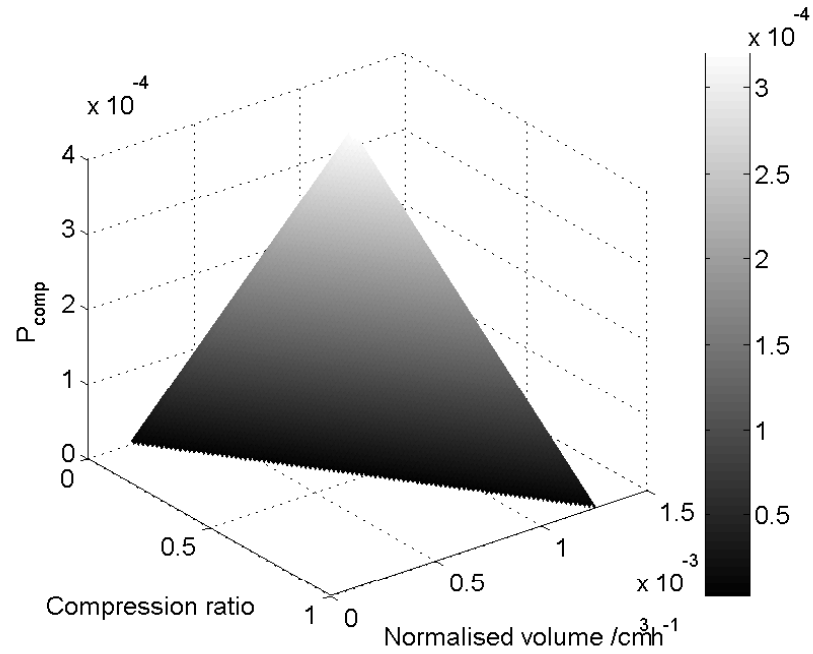

Fig. 6. Maximum power for compression against compression ratio and battery volume normalised to lifetime for a battery with energy density equal to $1100 \mathrm{~J} / \mathrm{cc}$, and a transmitter which consumes $5 \mathrm{~nJ} / \mathrm{b}$.

or battery volume possible for varying compression ratios, and give the corresponding power available to perform this compression. It is shown that data compression ratios of between 0.2 and 0.4 using only a few hundred microwatts can significantly improve the lifetime for a given battery size in the case of a $50 \mathrm{~nJ} / \mathrm{b}$ transmitter. Such compression would make it feasible to operate a wireless headset from a small coin cell for about a day and from a large coin cell for up to two weeks. For the $5 \mathrm{~nJ} / \mathrm{b}$ transmitter compression algorithms could consume no more than a few tens of microwatts to significantly increase the ratio of lifetime to battery size.

\section{REFERENCES}

[1] C. D. Binnie and H. Stefan, "Modern electroencephalography: Its role in epilepsy management," Clinical Neurophysiology, vol. 110, pp. 1671-1697, 1999.

[2] E. Waterhouse, "New horizons in ambulatory electroencephalography," IEEE Engineering in Medicine and Biology Magazine, pp 74-80, May/June 2003.

[3] Personal communication with Dr. Shelagh Smith, Consultant neurologist, National Society for Epilepsy, Chalfont St. Peter, UK.

[4] Ambulatory EEG, R \& D Fact sheet, IMEC 2004 [online]. Available at: http://www.imec.be/human/

[5] R. R. Harrison and C. Charles, "A low-power low-noise CMOS amplifier for neural recording applications," IEEE Journal of SolidState Circuits, vol. 38, no. 6, pp 958-965, June 2003.

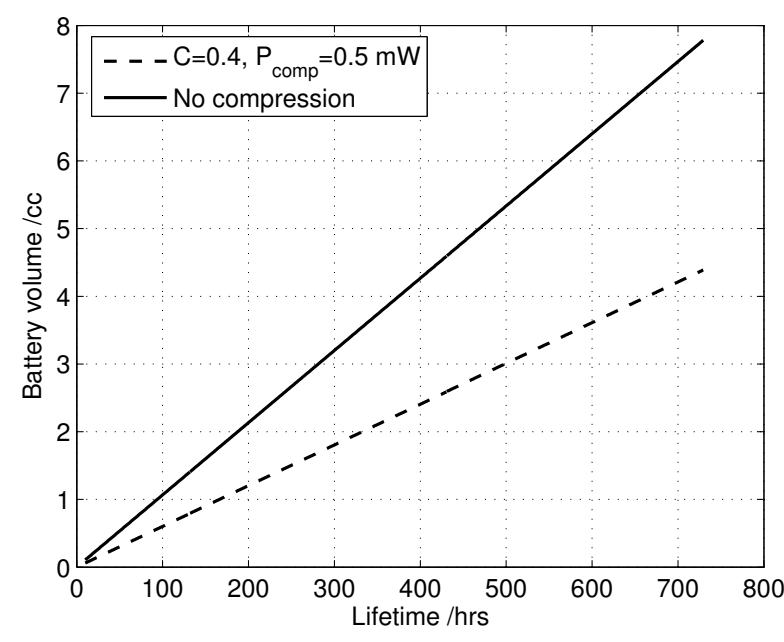

Fig. 7. Comparison of required battery volume for a given lifetime with and without compression for an energy density of $1100 \mathrm{~J} / \mathrm{cc}$ and a transmitter which consumes 50 nJ.b.

[6] D C Yates and E. Villegas-Rodriguez, "An ultra low power low noise chopper amplifier for wireless EEG," Invited Paper, 49th IEEE Midwest Symposium on Circuits and Systems, Suan Juan, Puerto Rico, Aug 6-9, 2006.

[7] J. Sauerbrey, D. Schmidt-Landsiedel and R. Thewes, "A 0.5 V 1 $\mu \mathrm{W}$ Successive Approximation ADC," IEEE Journal of Solid-State Circuits, vol. 38, no. 7, pp 1261-1265, July 2003.

[8] Product specification: Single-chip $2.4 \mathrm{GHz}$ Transceiver, Nordic Semiconductor 2004 [online]. Available: http://www.nordicsemi.no

[9] Bluetooth solutions from Texas Instruments, Product bulletin, Texas Instruments 2004 [online]. Available: http://focus.ti.com/

[10] XS110 UWB solution for media-rich wireless applications, Freescale Semiconductor 2004 [online]. Available: http://www.freescale.com/

[11] Zarlink ZL70100 Datasheet (2005, May). [Online]. Available at: http://www.zarlink.com/

[12] R. Cooper, J. W. Osselton and J. C. Shaw, EEG Technology, Second Edition, Butterworth \& Co., London 1974

[13] S. Roundy, D. Steingart, L. Frechette, P. Wright and J. Rabaey, "Power Sources for Wireless Sensor Networks," Book Series Lecture Notes in Computer Science, vol. 2920/2004, pp 1-17, Springer Berlin/Heidelberg 2004.

[14] G. Antoniol and P. Tonella,"EEG data compression techniques," IEEE Transactions on Biomedical Engineering, vol. 44, no. 2, pp. 105114, 1997.

[15] J. Cardenas-Barrera, J. Lorenzo-Ginori, and E. Rodriguez-Valdivia, "A wavelet-packets based algorithm for EEG signal compression" Medical Informatics and the Internet in Medicine, vol. 29, no. 1, pp. 1527, 2004.

[16] D. Gopikrishna and Anamitra Makur, "A high performance scheme for EEG Compression using a multichannel model," Lecture Notes in Computer Science, Volume 2552/2002, pp 443-451, 2002. 